\title{
KINETIC FACADES: HOW NATURE OF COMPONENTS AFFECTS THE APPLICATIONS OF DIFFERENT TRANSFORMATION STRATEGIES
}

\author{
Ahmed Abdelwahed Mekhamar 1, Ahmed Halim Hussein 2, \\ 1 Assistant lecturer, 2 lecturer \\ Architecture Dep., Faculty of Engineering-Mattaria, Helwan University
}

\begin{abstract}
In the current trend towards implementation of kinetic elements in buildings facades, a significant role is played by materials characteristics of integrated elements, and its effect on the responsive behavior of kinetic facades towards varying ambient conditions, represented through its motion and transformation strategies. After reviewing a wide range of kinetic facades researches, it was noticed that different research methodologies have been adopted mainly to study the apparent and general characteristics of kinetic facades, to represent an outline of movable facade's configurations and patterns morphology or to study different stimuli types and control strategies. While this paper's main aim is to provide researchers and designers, who are interested in the design and applications of kinetic facades with an overview of the interconnected relation between applied materials and different transformation strategies of kinetic facades.

The framework is divided into two parts at which the first part is considered to be a descriptive display of a number of remarkable case studies with different integrated materials and transformation strategies, while the second part is a comparative analysis of facades behavior, followed by a discussion, which proposes elements with different materials characteristics that can be applied to achieve specific scope of movements.
\end{abstract}

Keywords: Kinetic Facades, Materials, Nature of components, Transformation Strategies.

\section{1- Introduction:}

Buildings static nature have always been there, and have always been the challenge that architects and engineers tries to manipulate in order to be able to respond to nature in a more dynamic way. This innovation in kinetic design has led to the continuous search for the utilization of new materials into dynamic and kinetic facade strategies for the purpose of increasing buildings energy efficiency through responding to external climate factors also in order to meet occupant's needs and increase their comfort level without depending on non-renewable energy sources. 
In adaptive architectural facades design, the significance of patterns composition has mainly been based on the interrelationships between parts which forms the final whole composition. The aim of this paper is not to outline certain rules defining a type nor to standardize or enlist all the available movement patterns and accurately study their technical specifications; but rather to highlight the significant role different materials can play in the application of adaptive responsive facades and its effect on the different transformation strategies, to help in defining distinctions and establishing relationships between existing models and their movement patterns, as well as identifying the essential key features for providing a general simulation framework.

\subsection{Kinetic Facades:}

In Kinetic design has changed the idea of creating static structures that cannot meet the ever changing occupant's demands and environmental variations, by designing interactive and kinetic structures that can adaptively respond to both external climate conditions, user's demands or aesthetic concepts. Multidisciplinary studies proved that equipping building's structural elements with multiple types of movement mechanisms facilitates the innovation in creating new kinetic and adaptive building shells that requires the least energy to perform motion in response to design demands, user requirements and/or environmental influences.

Architects and designers need to understand more about materials characteristics and to be more involved in the design process of the form itself, its movement patterns, components, construction methods, and implementation techniques, in order to help in the realization process of efficient adaptive facades, through exploring more about materials behaviors and developing new approaches based on the design of elements movement. The nature of components plays a significant role in the application and performance of kinetic facades, thus the relation between nature of components and transformation strategies (Fig.1), illustrated in the impact of material's behavior on dynamic façade mechanisms shall be initially studied and then integrated in the context of the entire facade form so as to sustain the overall design configuration.

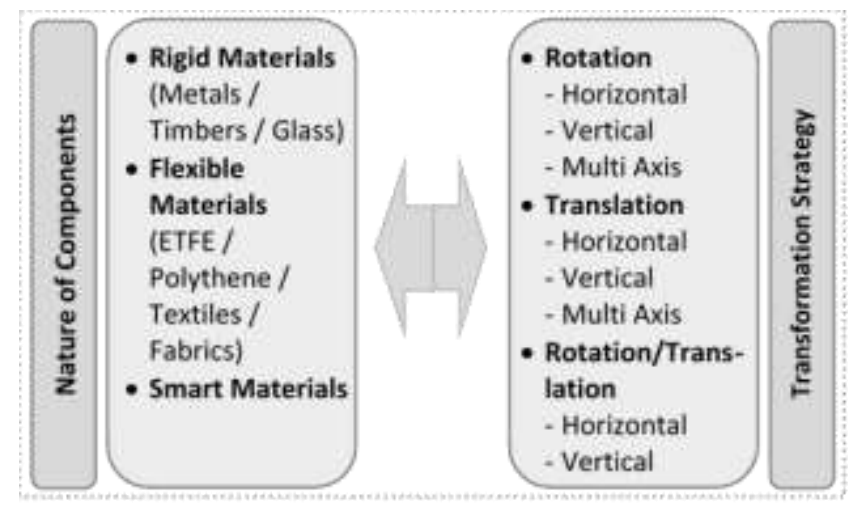

Table 1 displaying the interconnected relation between nature of components and transformation strategies in kinetic facades. 


\section{Nature of Components:}

In the recent era, Kinetic design has displayed an enormous potential shown in different architectural features such as elements, details, patterns and configurations. The ability of designing different forms of flexible, dynamic and kinetic structures have been possible by the integration of new technologies in kinetic design. At which the morphology of patterns and modules connecting between elements as well as the motion transmission strategies and technologies can be affected deeply by both the implemented structure and used materials, which enhances the significance of establishing a detailed understanding analysis of materials to obtain the desired kinetic structure.

Modularity certainly plays a fundamental role in the performance of kinetic architecture, as physical motion needs to be achieved through the transmission of movement from one element to another, at which there can be a wide range of transformative abilities embraced by different kinetic components. The ability of such components to modify their physical characteristics is highly affected by the applied materials and by the way the parts of the kinetic system are connected together. In architectural kinetic systems and structures, the form of materials and their morphological patterns are used in serving the idea of movement transmission, and the properties of materials is directly related to structure system's dynamics. As with the increase of the flexibility of materials, the link between the connected elements increases as well, which gives the opportunity of creating sophisticated applications for accomplishing the dynamic equilibrium. In this part of the chapter we are going to illustrate the most common types of kinetic materials that have been mostly used are listed below:

\section{- Rigid Materials:}

The usually depends in its movements on kinetic mechanisms such as hinges or joints which allow the transmission of movement from one part to the other, such materials can be effectively used to perform the folding, rotational or sliding types of motion. The most common examples of rigid materials are metals, timber and glass. At which its operation in architecture is composed of an arranged array of different components grouped together to form a certain pattern for the purpose of transmitting motion from one part to another in a certain manner, accomplishing the desired function of the system.

An example of the application of metals in kinetic façade shading is the Q1 headquarters building in Germany (Fig.2a), the building has an innovative sun shading system which consists of 400,000 stainless steel lamellas made of horizontal cantilevered slats [1]. While in Elysium Lot in Australia (Fig.2b), openings at the long axis of the building are finely screened with vertical timber folding panels [2]. and in The Oval Offices in Cologne (Fig.2c.), building's external facades are covered by a vertical axis glazed sun louvers to provide daylight control [3].

\section{- Flexible Materials}

Its characteristics allow nature of components and transformation strategies in kinetixxternal forces, without losing their $\mathrm{o}$ facades.

architecture are mainly divid

lied in ements 
that can allow the transmission of movement through different motion concepts such as folding, creasing, bending or inflating. At which fibers, cords or ropes are common examples of linear elements while ETFE, polythene sheets, textiles and fabrics are examples of flat elements.

An example of the application of flexible materials in kinetic façades is the Nature Concert Hall in Latvia (Fig.2d) which is a modular pavilion, its façade is made of vertical fabric bars that can be rotated in response to the natural movement of the wind and with respect to surrounding environments [4]. Another example is the One Ocean kinetic façade in South Korea (Fig.2e) that is made-up of glass fiber reinforced polymers (GFRP) vertical slightly curved plates that are capable of being morphed due to compression forces which creates complex elastic deformations to control daylight penetration during the day [5].

\section{- Smart/Intelligent Materials:}

A wide range of new, innovative smart materials have evolved in response to the significant advances in nanotechnology and biomimicry design. Smart materials characteristics allow them to create motion and transmit it through changing their own physical structure, appearance or properties in response to external forces and stimuli.

An example of the applications of smart materials is the "HygroScope: Meteorosensitive Morphology" at the Centre Pompidou in Paris [6] (Fig.2f). The used material is a combination of quarter sliced maple veneer and synthetic composites, at which the composite layers are manufactured to be assembled into four to seven sided polygons that have the ability to open and close in response to surrounding relative humidity.
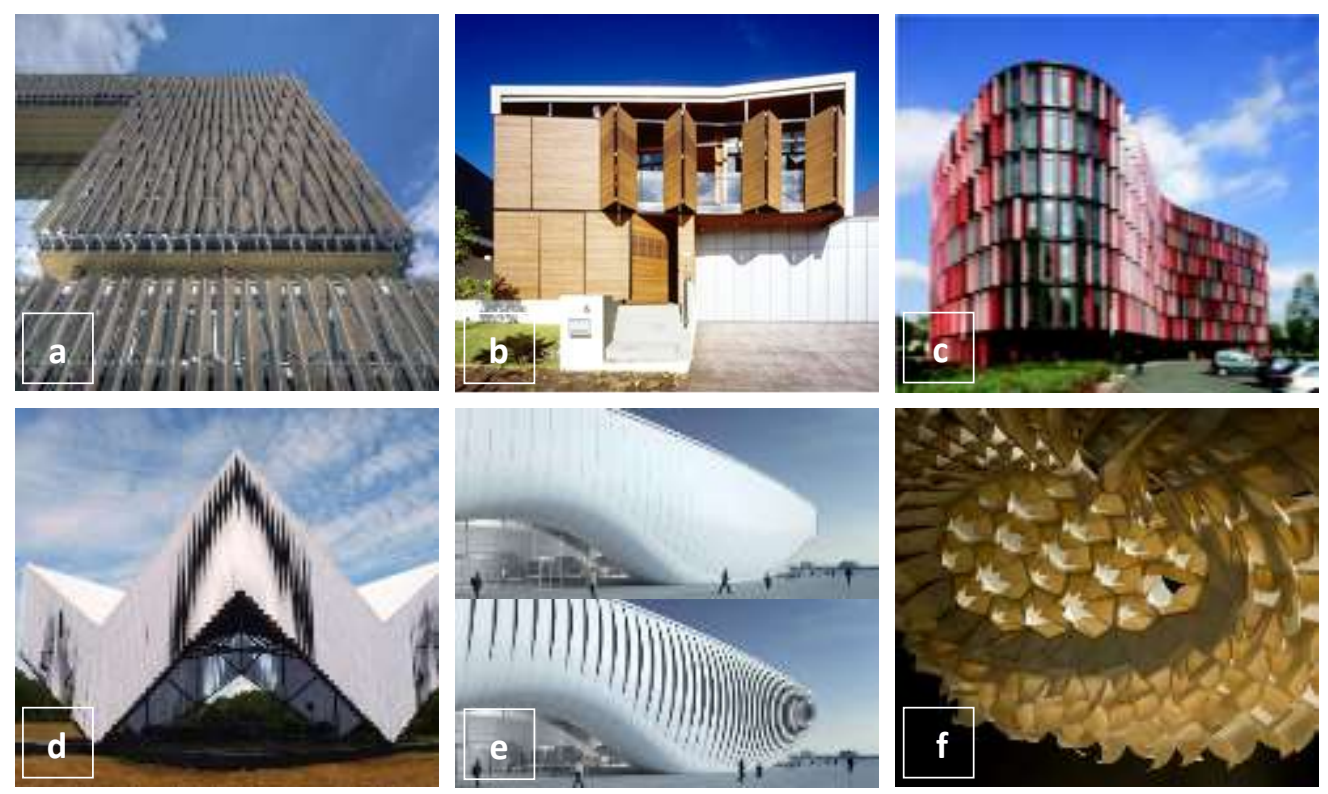

Figure 2 (a) Q1 headquarters building in Germany [7] (b) Elysium Lot in Australia [8] (c) Oval Offices in Cologne [9] (d) Nature Concert Hall [10] (e) One Ocean kinetic façade in South Korea [11 (f) "HygroScope: Meteorosensitive Morphology" at the Centre Pompidou in Paris [12] 


\section{Transformation Strategies:}

Kinetic architecture's transformation strategies is more complicated than the simple integration of movable structures in buildings .as it is consisted of complex transformable spatial experiences, at which the created motion in kinetic architecture is transformed in response to different affecting variable internal or external stimuli. Structures integrated in the applications of kinetic architecture, can have the ability to modify their size, orientation or shape and accomplish movement mainly through transforming their geometrical patterns or modularity. Different types of material can be applied to perform mechanical movements, examples of this materials can be rigid, flexible and elastic bodies. Mechanical movements of kinetic structures can be categorized into two main types, i.e. translation and rotation. (Fig.3).

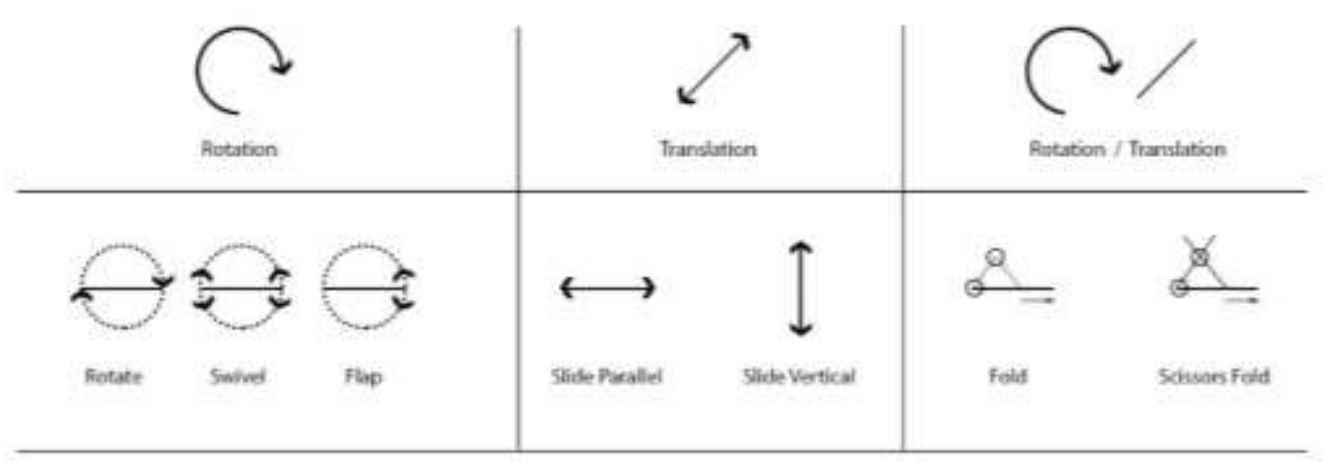

Figure 1 Rigid materials transformation strategies

The illustrated table clarifies the two main typologies of movements as follows, the first type is the tri-dimensional change of shape and is addressed by rotational movement, it performs swivel motion both in the same axis and/or around a different axis. Translational movement is the second type; it is achieved through the bidimensional change of shape. It is usually linear and allows adjustment levels in the building skins by overlapping layers and by size-opening variation. Each one of the two discussed main typologies of movements has different degrees of movement freedom according to their structural constrains and geometrical patterns. Based on this, combining the two typologies of translational and rotational movements together, can provide a wide range of new movements that could be achieved through this integration. Different degrees of freedom can be achieved, and different typologies of movement can be defined as well, and several possible simple and complex movements along with a wide spectrum of transformations can be obtained from applying single method of movement such as rotation or translation or from combining both methods together.

\section{- Rotation:}


There are two types of rotation techniques implementations in kinetic adaptive facades, at which the unit itself can rotate around a single vertical or horizontal axis to accomplish the goal of the motion itself, Examples of the two types are listed below:

In SDU University of Southern Denmark (Fig.4a) the campus is fitted with dynamic solar shading system, with 1600 triangular perforated steel panels that are able to adjust itself to desired daylight penetration through rotating around a vertical axis [13]. While a Perforated metal horizontally rotating louver shading system is integrated on the external glazed façade of the Zurich Airport, Switzerland [14] (Fig4.b).

\section{- Sliding:}

There are two common types of sliding strategies implementations in dynamic adaptive facades, the first one is the one axis sliding, at which the elements in the external façade can slide in one direction to create a $2 \mathrm{~d}$ simple motion. While the second strategy is the multi axis sliding, at which the kinetic shading elements have the ability to slide in more than only one direction, this ability expands the variety of patterns motion configurations that could be achieved.

In Situla Housing and Office Complex (Fig.4c) the building facade design is composed of an enclosure of copper/bronze colored perforated aluminum panels which slides horizontally along the main façade [15], providing shade and controlling daylight. While the Adaptive Building Initiative (ABI), Tessellate adaptive facade installation, (Fig.4d) which is an application of the concept of multi axis sliding strategy [16]. Tessellate is composed of panels that slide and overlap over each other creating shade through the change of its morphological patterns.

\section{- Folding:}

Folding movement technologies implementations in kinetic architecture, most commonly encompasses structures made from flexible materials or rigid materials that are integrated in a way that makes it possible to crinkle or crease so that it comes into contact with itself and decrease the area of coverage. There are two types of the implementations of folding mechanism, horizontal and vertical.

A significant example is the CJ Research Center's Folding Facade in Korea (Fig.4e) the special custom designed kinetic shading system folds vertically with an accordion/umbrella concept [17], it is manufactured from perforated steel strips that are installed on scissor actuators which facilitates the opening and closing process and ensures the penetration of the most proper natural lighting levels. While in the Technical University in Graz (Fig.4f) the southern facade is entirely glazed and screened by an adaptive external vertical kinetic vertical folding shading system made of movable perforated aluminium panels[18].

Al Bahar Towers Responsive Façade (Fig.4g) is a remarkable example of origami shading, it is composed of a unique shading screen composed of a group of triangles placed two meters outside the buildings' exterior on an independent frame[19]. Each one of the triangles is folded in a multi axis direction and programmed to move in accordance to the movement of the sun. 

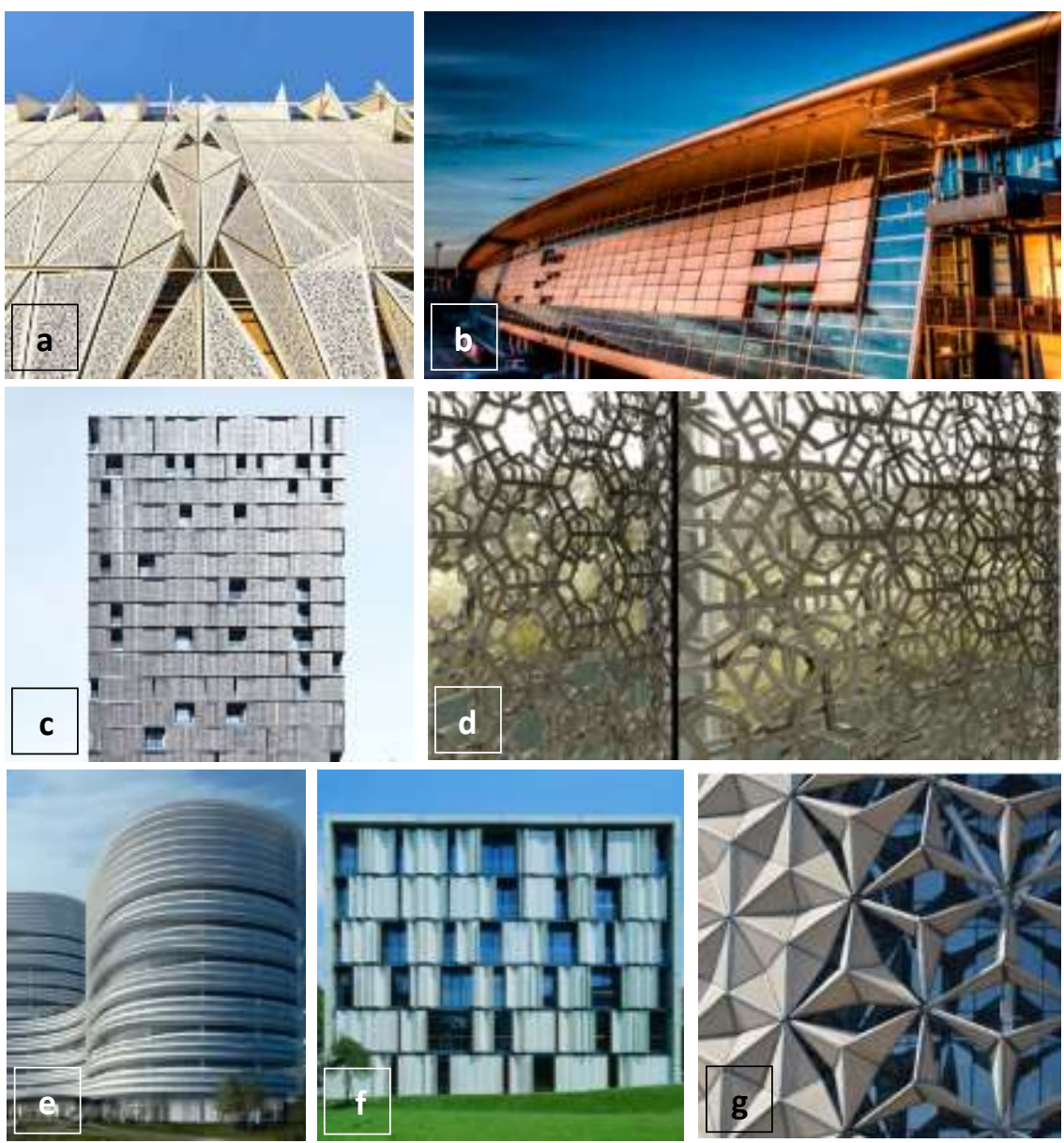

Figure 4 (a) SDU University of Southern Denmark [20] (b) Zurich Airport in Switzerland [21] (c) Situla Housing and Office Complex [15] (d) Tessellate adaptive facade installation, Simons [22] (e) CJ Research Centre's Folding Facade in Korea [23] (f) Technical University in Graz [24] (g) Al Bahar Towers [25]

Other concepts of transformation strategies other than the two previously discussed movement typologies can be obtained either from the type of movement achieved from the combination of a group of rigid elements together to form a flexible shape or form the inner characteristics of specific materials with either flexible, smart/intelligent or intrinsic properties that allows them to accomplish different types of movements. Existing case studies of some of the types of these movements such as bending / deformation, retracting and inflation / deflation are listed below and discussed for better concept clarification.

\section{- Bending / Deformation:}

Active bending is a kinetic structural response that could be achieved through either the use of flexible materials or the utilization of large elastic deformations of a group of elements combined together to create a three-dimensional form from 
initially rigid flat or linear elements. Bending-active structures can be fabricated out of either flat plates or rods, which facilitates their fabrication process, transportation and assembly.

An example of the active bending structural movement is the Undulatus pavilion (Fig.5a), it is a lightweight structure that integrates the bending principle in a kit-ofparts system. It is fabricated through the cut out of flat plates, and the small parts are folded along a set of predefined curved lines to form a weave pattern being connected 'flap to leg' respectively [26]. The resulting deformed geometry, creates an efficient 'building block' that can be integrated in different ways to create different structural configurations

\section{- $\quad$ Retracting}

The application of retracting motion in kinetic applications, is identified as the type of motion that is associated with deployable structures which creates responsive actions. A remarkable example of the retracting movement of smart materials in adaptive façades is the HygroSkin Pavilion (Fig.5b) the pavilion's building skin is made of conical plywood panels produced through the elastic bending of planar sheets which has intrinsic properties that allows it to respond directly to relative humidity from 30 to $90 \%$ to control the opening and closing of façade elements [27].

\section{- Inflation/Deflation:}

Inflation and deflation strategies implementations in kinetic architecture, most commonly Involves flexible materials with special properties expanding, contracting, inflating or deflating to accomplish the needed purpose. Media TIC Building in Barcelona (Fig.5c) is a significant example of the application of inflation and deflation in architecture. The building's south-east façade is formed of concave and convex triangles that are manufactured of eco-efficient material ethylene-tetra-fluoroethylene (ETFE) cladding "skin" which consists of air chambers that have the ability to be inflated and deflated through the change in air pressure within [28].

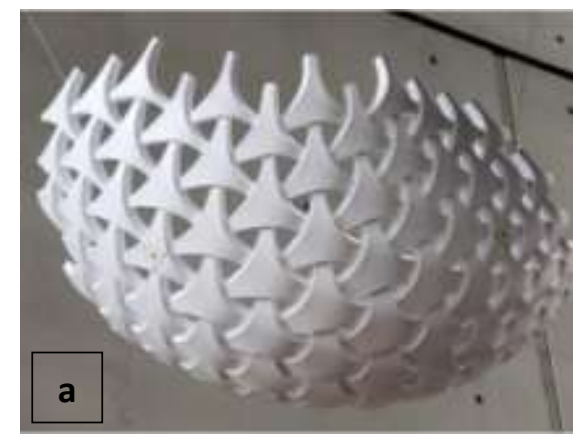

Figure 5 (a) The Undulatus pavilion [29]
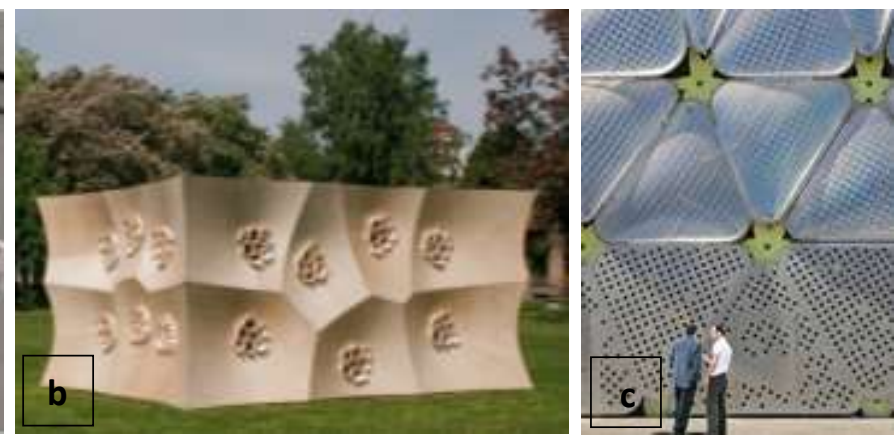

The study of the interconnected relation between applied materials and different transformation strategies of kinetic elements in adaptive facades discussed 
in this paper, is summarized in (Table1) which assemble an overview of all of the existing case studies clarified in the paper in a simple display while highlighting the main differences and its effect on both of the materials behavior and elements performance.

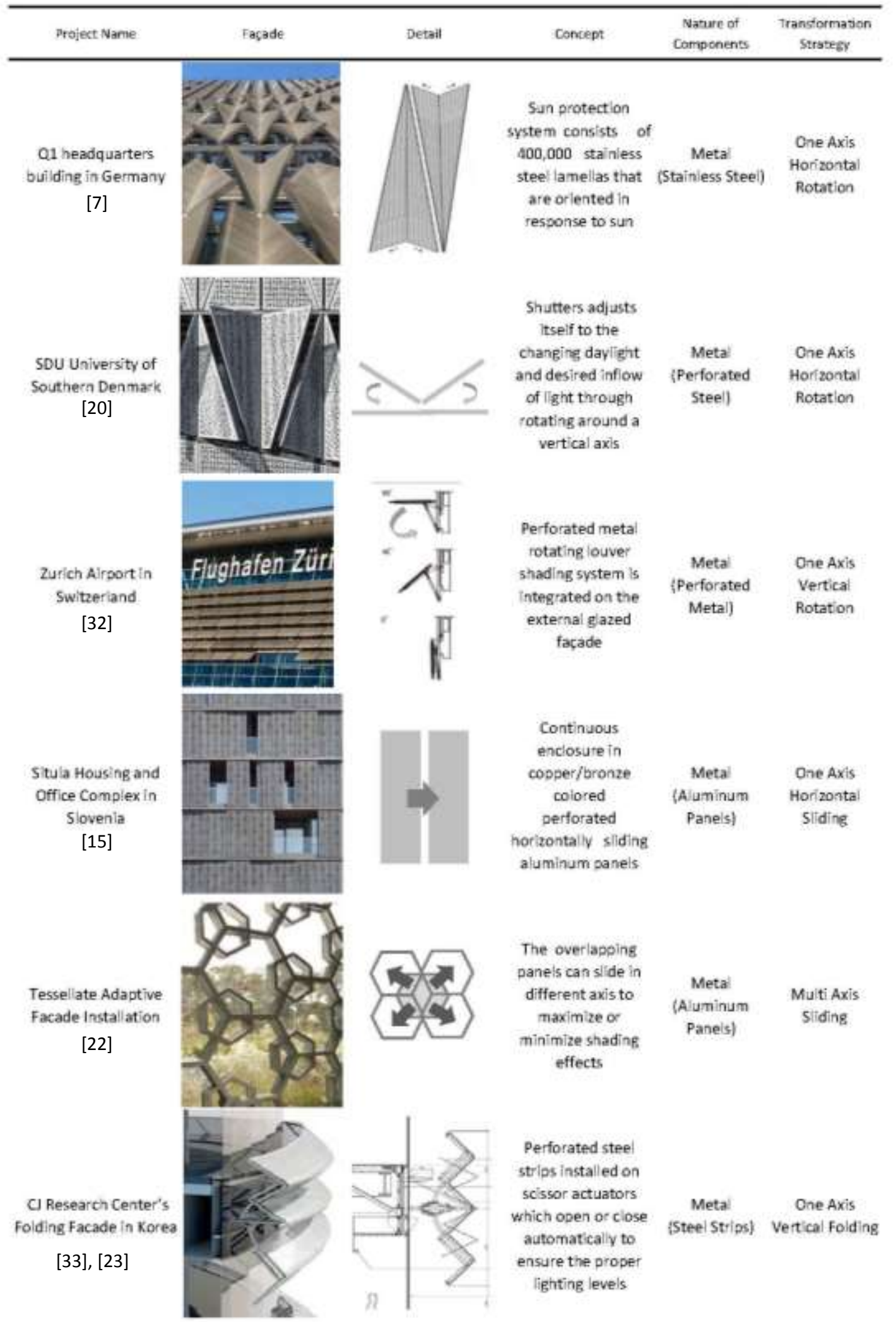


Ahmed Haleem Hussien / Engineering Research Journal 170 (June 2021) A11-A25

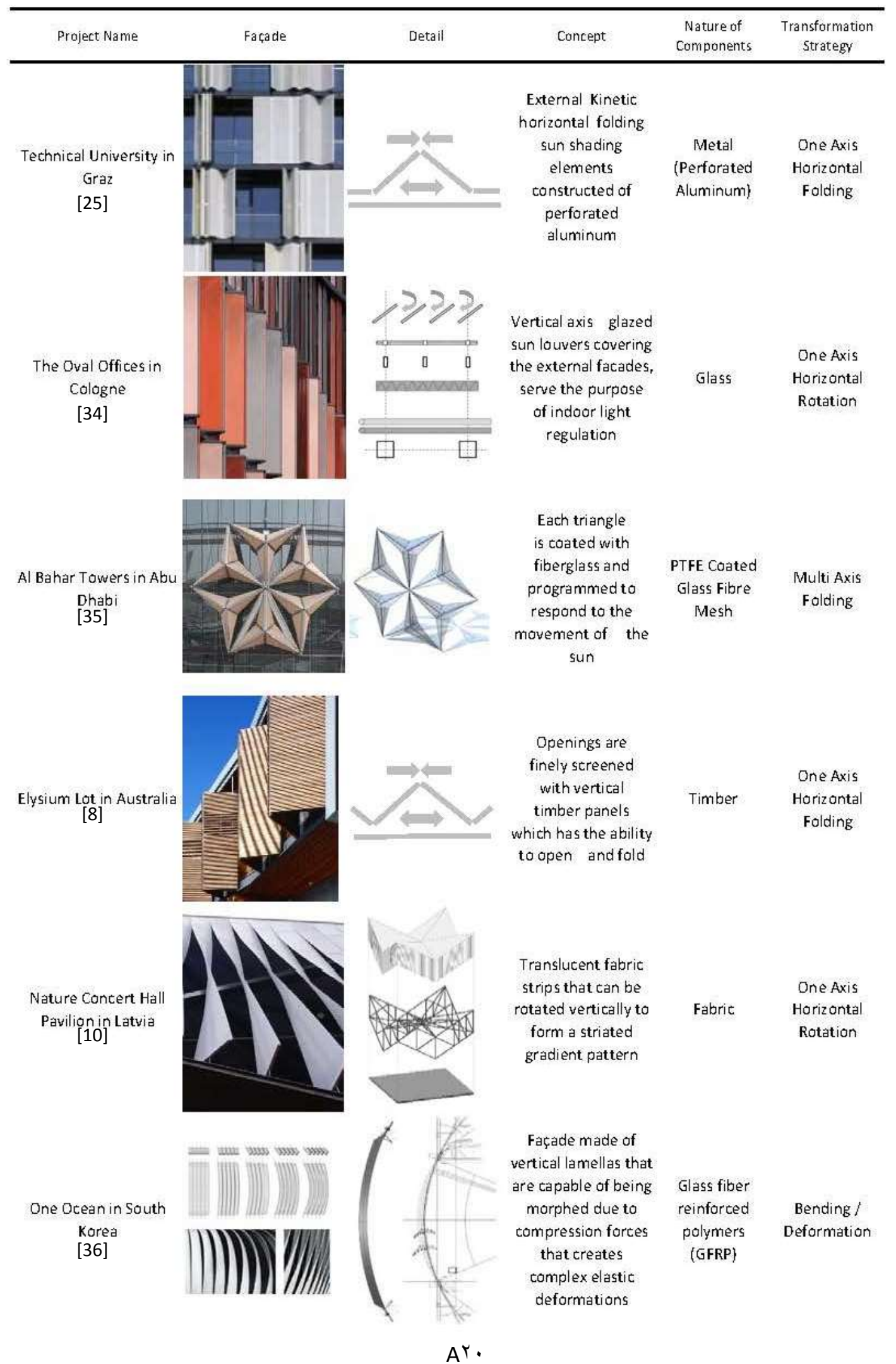




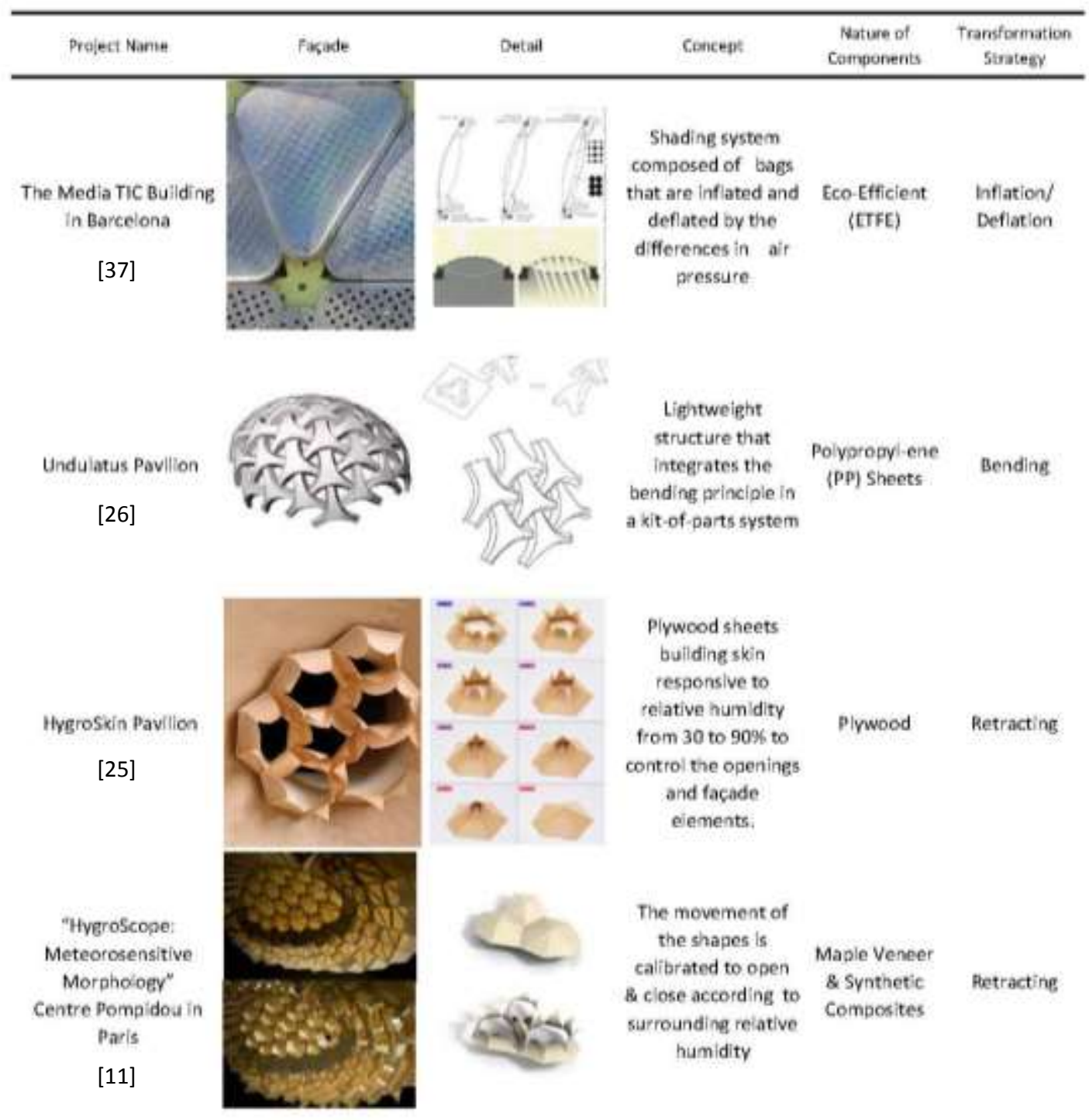

\section{Discussion:}

Based on the analysis of a number of existing case studies discussed in this paper, it can be concluded that there is a specific scope of movements that is utilized with the integration of each specific material according to its inner characteristics and behavior when being displayed to different external forces or stimuli. From the case studies clarified in the table above it can be noticed that the most commonly used rigid materials in the applications of rigid kinetic facades is metal at the first place (Q1 headquarters, SDU University, Zurich Airport, Situla Housing and Office 
Complex, Tessellate installation, CJ Research Center and Technical University in Graz), glass (The Oval Offices and Al Bahar Towers) and timber (Elysium Lot), due to the availability of rigid materials and ease in manufacturing and customization. The scope of motion of such elements is mainly confined to two main transformation strategies which are as follows: (rotation, translation, rotation / translation), at which rigid façade elements usually have extrinsic control, elements are moved by actuators (can be completely embedded into the device or strategically located to trigger a specific action) and controlled by integrated computer systems to respond to different external/internal stimuli.

While the adoption of light- weight flexible and elastic materials allows the fabrication of components to different desired shapes that can be tamed to realize different shapes and design morphologies, still it is not very commonly applied in kinetic facades as much as rigid materials. Examples of flexible materials are fabrics (Nature Concert Hall) along with different innovative materials such as ETFE and GFRP that have been recently emerged due to the innovation in technology that have been recently integrated in different forms of both passive and kinetic architecture (One Ocean kinetic façade and Media TIC Building). The movement of flexible materials can be either from direct influence of natural climatic forces or from computer controlled actuators which initiate the movement of flexible elements, allowing its own characteristics to respond in a flexible manner. Different types of flexible materials can be created through the combination of a group of rigid elements together in a single form to create a whole form that have the ability to respond in a flexible behavior to external kinetic forces such as the active bending movement created by the Undulatus Pavilion.

The last discussed type of materials is that with inner intrinsic properties, at which the material itself can have the ability to respond to external stimuli without the requirement of any mechanical or electric input. Such type of materials still needs profound and extensive study and investigation. Due to its unique applications and characteristics this type is not commonly applied in architectural kinetic facades ("HygroScope: Meteorosensitive Morphology" at the Centre Pompidou and HygroSkin Pavilion).

\section{Conclusion:}

The attention given to improving building energy performance in the last decades has led to the emerge of new adaptive and kinetic building envelopes. In the case of kinetic architecture, transformation strategy is a fundamental property due to the pragmatic need of a series of movement patterns being transmitted from one element to the next. In order to achieve physical motion, these modules or components must embrace a wide range of transformations, as their ability to modify their own physical characteristics can be directly affected by different materials used to create motion in kinetic façades. A wide range of innovative rigid, flexible and smart materials have been implemented and applied, the impact of such different materials characteristics and behavior under changing circumstances and external forces on kinetic facades performance and motion techniques is considered to be a significant research area and a promising study field. 
This paper aims to reveal through the study conducted on a representative sample of existing kinetic facades and architectural elements, the important role which the interconnected relation between material's characteristics and kinetic façade transformation strategies have on the efficiency of dynamic façade's performance and applications. Thus precisely choosing applied materials can help in understanding the capability and optimizing the performance of responsive kinetic facades.

\section{REFERENCES:}

[1] Marwa N. Charkas, Towards Environmentally Responsive Architecture: A Framework For Biomimic Design of Building's Skin, Faculty of Engineering, Pharos University, Alexandria, Egypt, Journal of Engineering Sciences Assiut University Faculty of Engineering, Vol. 47 No. 3 May 2019.

[2] Mark Cleary, 21st Century Houses Downunder, Published in Australia , 2010.

[3] R.C.G.M. Loonen, J.M. Rico-Martinez, F. Favoino, M. Brzezicki, C. Menezo, G. La Ferla, L. Aelenei, Design for façade adaptability - Towards a unified and systematic characterization, Conference Paper · October 2015.

[4] A llze Rukmane-Poča, Linda Leitāne-Šmīdberga, The Directions of Formal Expression in Latvian Contemporary Architecture in the Context of the Synthesis of the Arts, Riga Technical University, Architecture and Urban Planning, 2015.

[5] Marlén López, Ramón Rubio, Santiago Martín, Ben Croxford, How plants inspire façades. From plants to architecture: Biomimetic principles for the development of adaptive architectural envelopes, Renewable and Sustainable Energy Reviews, 2017.

[6] Nicola Augustin, Motion with Moisture Creating Passive Dynamic Envelope Systems Using the Hygroscopic Properties of Wood Veneer, Master of Architecture Waterloo, Ontario, Canada, 2018.

[7] Fahad Alotaibi, The Role of Kinetic Envelopes to Improve Energy Performance in Buildings, Architectural Engineering Technology, Volume 4, Issue 3, 2015.

[8] Elysium Lot in Australia , https://www.archdaily.com/227564/elysium-richard-kirkarchitect/5017ea4e28ba0d49f5000f98-elysium-richard-kirk-architect-photo?next_project=no (Accessed on 5/8/2020).

[9] Anna Sandak, Jakub Sandak, Marcin Brzezicki, Andreja Kutnar, State of the Art in Building Façades, Bio-based Building Skin, March 2019.

[10] Latvia's Nature Concert Hall has a fabric skin, https://trends.archiexpo.com/project-240289.html (Accessed on 5/8/2020).

[11] Jan KNIPPERS, Florian SCHEIBLE, Matthias OPPE, Hauke, JUNGJOHANN, Bio-inspired Kinetic GFRP-façade for the Thematic Pavilion of the EXPO 2012 in Yeosu, Conference Paper - May 2012.

[12] SteffenReichert, AchimMenges, DavidCorrea, Meteorosensitive architecture: Biomimetic building skins based on materially embedded and hygroscopic ally enabled responsiveness, Computer-AidedDesign, 2015.

[13] E V Pimenova, The use of transformable systems in the architecture of buildings of educational organizations, Don State Technical University, Russia, IOP Conference Series: Materials Science and Engineering, 2019.

[14] Joud Al Dakheel and Kheira Tabet Aoul, Building Applications, Opportunities and Challenges of Active Shading Systems: A State-Of-The-Art Revie, review, Energies, 2017.

[15] ŠTROVS, N., 2014. The Situla Building, Ljubljana, Uncube. Retrieved 20 August., 2020, http://www.uncubemagazine.com/blog/12155631, (Accessed on 5/8/2020). 
[16] B. Kolaveric, V. Parlac, Adaptive, Responsive Building Skins, in Building Dynamics: Exploring Architecture of Change, Routledge Taylor \& Francis Group, London and New York, 2015, Chapter 12, pp. 69-88.

[17] Naglaa Megahed, A Swot Analysis of Responsive Shading Systems with Umbrella Concepts. Architecture and Urban Planning Department, Port Said, Egypt, International Conference on Architecture, Landscape \& Interior Design, 2017.

[18] Wyckmans, A., Intelligent building envelopes. Doctoral thesis, Dept. of Architectural Design, History and Technology, Norwegian University of Science and Technology, Norwegian, 2005.

[19] A Shady Attia, Evaluation of adaptive facades: The case study of Al Bahr Towers in the UAE, Research article, QScience Connect , 2017.

[20] SDU University of Southern Denmark, Campus Kolding, Denmark, http://arcdog.com/portfolio/sdu-university-of-southern-denmark-campus-kolding/ (Accessed on 20/8/2020).

[21] Joud Al Dakheel and Kheira Tabet Aoul, Building Applications, Opportunities and Challenges of Active Shading Systems: A State-Of-The-Art Review, energies, 23 October 2017.

[22] Adaptive Building Initiative (ABI), Tessellate, adaptive facade installation, Simons Centre for Geometry and Physics, Stonybrook University, New York, 2010.

[23] CJ Research Centre's Folding Facade, https://yazdanistudioresearch.wordpress.com/2011/11/15/cj-rd-centre-kinetic-façade/ (Accessed on 5/9/2020).

[24] The Biokatalyse at Technical University Graz, https://www.e-architect.co.uk/austria/biocatalysis-technical-university-graz (Accessed on $6 / 9 / 2020)$.

[25] Shady Attia, Evaluation of adaptive facades: The case study of Al Bahr Towers in the UAE, QScience Connect, Shaping Qatar's Sustainable Built Environment, 2017.

[26] Brancart, S., Vergauwen, A., Roovers, K., Van Den Bremt, D., De Laet, L. \& De Temmerman, N., UNDULATUS: design and fabrication of a self-interlocking modular shell structure based on curved-line folding. Future visions, Proc. intern. symp., Amsterdam, 2015.

[27] Steffen Reichert, Achim Menges, David Correa, Meteorosensitive architecture: Biomimetic building skins based on materially embedded and hygroscopically enabled responsiveness, Institute for Computational Design (ICD), University of Stuttgart, Germany, Computer-Aided Design, 2015.

[28] Sachin Harry, Dynamic Adaptive Building Envelopes - an Innovative and State-of-The-Art Technology, School of Planning \& Architecture, Chitkara University, Rajpura, India, Creative Space Vol-3, No-2, 2016.

[29] UNDULATUS: design and fabrication of a self-interlocking modular shell structure based on curved-line folding, S. BRANCART, A. VERGAUWEN, K. ROOVERS, D.VAN DEN BREMTB, L. DE LAET , N.DE TEMMERMAN., Proceedings of the International Association for Shell and Spatial Structures (IASS), Amsterdam Future Visions, 17 - 20 August 2015.

[30] Oliver David Krieg, Zachary Christian, David Correa, Achim Menges, Steffen Reichert, Katja Rinderspacher, Tobias Schwinn, HygroSkin - Meteorosensitive Pavilion, Institute for Computational Design, University of Stuttgart, Germany.

[31] Addington and Schodek, (2009), Smart Materials, Berlin: Birkhauser T. press, p.22.

[32] Zurich Airport in Switzerland, https://www.dreamstime.com/photos-images/zurich-airportswitzerland.html, (Accessed on 1/9/2020). 
[33] CJ Research Centre's Folding scissor detail, http://www.evolo.us/architecture/cj-researchcentres-kinetic-folding-façade-yazdanistudio/ (Accessed on 5/9/2020).

[34] Design for façade adaptability: Towards a unified and systematic characterization, 10th Conference on Advanced Building Skins, 3-4 November 2015, Bern, Switzerland.

[35] A. Wagdi ; Y. Elghazi ; S. Abdalwahab ; and A. Hassan, The Balance between Daylighting and Thermal Performance Based on Exploiting the Kaleidocycle Typology in Hot Arid Climate of Aswan, Egypt, Conference Paper · March 2015.

[36] One Ocean, Yeosu, MEDIA FACADES, PROJECTS, Media Architecture Institute, 2013

[37] ETFE dynamic solar shading in MediaTIC, Barcelona, https://www.filt3rs.net/case/etfe-dynamicsolar-shading-mediatic-barcelona-553, (Accessed on 1/10/2020). 